\title{
Commentary: Beyond appropriate use, excluding the useless
}

\author{
T. Brett Reece, MD
}

\author{
From the Division of Cardiothoracic Surgery, Department of Surgery, University of Colorado, Aurora, Colo. \\ Disclosures: Author has nothing to disclose with regard to commercial support. \\ Received for publication Jan 25, 2019; accepted for publication Jan 28, 2019. \\ Address for reprints: T. Brett Reece, MD, 12631 E. 17th Ave, MS C310, Room 6601, Aurora, CO 80045 (E-mail: \\ brett.reece@ucdenver.edu). \\ J Thorac Cardiovasc Surg 2019;157:1465 \\ $0022-5223 / \$ 36.00$ \\ Copyright (c) 2019 Published by Elsevier Inc. on behalf of The American Association for Thoracic Surgery \\ https://doi.org/10.1016/j.jtcvs.2019.01.104
}

The costs of delivering health care in the United States continue to escalate at alarming rates, with projections of health care representing $20 \%$ of gross domestic product by $2020 .{ }^{1}$ Although technology and medicolegal issues play significant roles, money spent on useless testing remains substantial, contributing as much as $20 \%-30 \%$ of wasted health care dollars. ${ }^{2,3}$ The reason for ordering these less beneficial tests is usually lack of awareness of test utility. The accompanying document is the second multidisciplinary document that attempts to address gaps in familiarity with optimal testing in nonvalvular heart disease. ${ }^{4}$ The first document addressed valvular heart disease, and the second document addressed the majority of other common pathologies seen in cardiology and cardiac surgery. ${ }^{5}$

The American College of Cardiology spearheaded the coordination of this document to include input from the full spectrum of physicians who care for cardiac pathologies. All parties had the specifics of studies within their comfort zone down, but there were many topics that even the rating group had to learn about best practices. For instance, the surgeons were very vocal about the current standards for dissection care, but other aspects were not as familiar. In these cases, evidenced-based arguments were made from the experts from subspecialties before voting on the appropriateness of different modalities specific to clinical scenarios. As with the valve-based criteria, the goal of this document is to help direct testing into modalities that provide some value to the patient and provider. As such, the recommendations allow for a variety of approaches for most every clinical scenario so that facilities or providers have options available to them.

The appropriate use guidelines should be viewed as resources to reduce wasted tests on patients. The development of these types of resources is intended to be beneficial for patients and providers rather than creating any restrictions on ordering. All of us want to do what is best for our patients, so hopefully this article aids in the optimal care of patients with nonvalvular heart disease both before and after

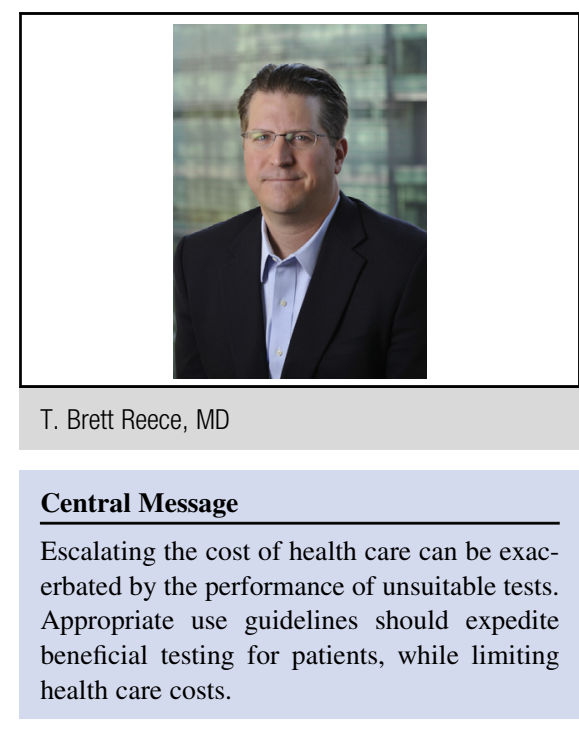

See Article page e153.

they are seen by cardiac surgeons with minimization of costly diagnostic testing that provides little to the optimal care of these patients.

\section{References}

1. Stagnitti MN, Carper K. National health care expenses in the U.S. civilian noninstitutionalized population, distributions by type of service and source of payment, 2012. In: Statistical Brief (Medical Expenditure Panel Survey [US]). Rockville, MD: Agency for Healthcare Research and Quality; 2001.

2. Evans RG. Waste, economists and American healthcare. Healthc Policy. 2013;9: 12-20.

3. Rehman H, Ali F, Mangi MA. Choosing wisely campaign - innovations in cardiovascular science and the United States healthcare system. Cureus. 2018;10:e2931.

4. Doherty JU, Kort S, Mehran R, Schoenhagen P, Soman P. ACC/AATS/AHA/ASE/ ASNC/HRS/SCAI/SCCT/SCMR/STS 2019 appropriate use criteria for multimodality imaging in the assessment of cardiac structure and function in nonvalvular heart disease: a report of the American College of Cardiology appropriate use criteria task force, American Association for Thoracic Surgery, American Heart Association, American Society of Echocardiography, American Society of Nuclear Cardiology, Heart Rhythm Society, Society for Cardiovascular Angiography and Interventions, Society of Cardiovascular Computed Tomography, Society for Cardiovascular Magnetic Resonance, and the Society of Thoracic Surgeons. J Thorac Cardiovasc Surg. 2019;157:e153-82.

5. Doherty JU, Kort S, Mehran R, Schoenhagen P, Soman P. ACC/AATS/AHA/ASE/ ASNC/HRS/SCAI/SCCT/SCMR/STS 2017 appropriate use criteria for multimodality imaging in valvular heart disease: a report of the American College of Cardiology appropriate use criteria task force, American Association for Thoracic Surgery, American Heart Association, American Society of Echocardiography, American Society of Nuclear Cardiology, Heart Rhythm Society, Society for Cardiovascular Angiography and Interventions, Society of Cardiovascular Computed Tomography, Society for Cardiovascular Magnetic Resonance, and Society of Thoracic Surgeons. J Am Coll Cardiol. 2017;70:1647-72. 